\title{
Determination of heat transfer coefficients in plastic French straws plunged in liquid nitrogen ${ }^{\text {th }}$
}

\author{
M. Victoria Santos ${ }^{\mathrm{a}, \mathrm{c}, *}$, M. Sansinena ${ }^{\mathrm{b}, \mathrm{c}}, \mathrm{J}_{\text {. Chirife }}^{\mathrm{b}}$, N. Zaritzky ${ }^{\mathrm{a}, \mathrm{c}}$ \\ a Depto. de Ingeniería Química, Facultad de Ingeniería, Universidad Nacional de La Plata and Centro de Investigación y Desarrollo en Criotecnología de Alimentos \\ (CONICET-UNLP), Calle 47 y 116, La Plata 1900, Argentina \\ ${ }^{\mathrm{b}}$ Facultad de Ciencias Agrarias, Pontificia Universidad Católica Argentina, Cap. Gral. Ramón Freire 183, CABA 1426, Argentina \\ ${ }^{\mathrm{c}}$ Consejo Nacional de Investigaciones Científicas y Técnicas, A. Rivadavia 1917, CABA 1033, Argentina
}

\section{A R T I C L E I N F O}

\section{Article history:}

Received 23 May 2014

Accepted 24 October 2014

Available online 31 October 2014

\section{Keywords:}

Surface heat transfer coefficient

Liquid nitrogen

Freezing

Cooling

French straws

Film pool boiling

Nucleate pool boiling

Finite element method

Boiling correlations

\begin{abstract}
A B S T R A C T
The knowledge of the thermodynamic process during the cooling of reproductive biological systems is important to assess and optimize the cryopreservation procedures. The time-temperature curve of a sample immersed in liquid nitrogen enables the calculation of cooling rates and helps to determine whether it is vitrified or undergoes phase change transition. When dealing with cryogenic liquids, the temperature difference between the solid and the sample is high enough to cause boiling of the liquid, and the sample can undergo different regimes such as film and/or nucleate pool boiling.

In the present work, the surface heat transfer coefficients $(h)$ for plastic French straws plunged in liquid nitrogen were determined using the measurement of time-temperature curves. When straws filled with ice were used the cooling curve showed an abrupt slope change which was attributed to the transition of film into nucleate pool boiling regime. The $h$ value that fitted each stage of the cooling process was calculated using a numerical finite element program that solves the heat transfer partial differential equation under transient conditions. In the cooling process corresponding to film boiling regime, the $h$ that best fitted experimental results was $h=148.12 \pm 5.4 \mathrm{~W} / \mathrm{m}^{2} \mathrm{~K}$ and for nucleate-boiling $h=1355 \pm 51 \mathrm{~W} / \mathrm{m}^{2} \mathrm{~K}$. These values were further validated by predicting the time-temperature curve for French straws filled with a biological fluid system (bovine semen-extender) which undergoes freezing. Good agreement was obtained between the experimental and predicted temperature profiles, further confirming the accuracy of the $h$ values previously determined for the ice-filled straw. These coefficients were corroborated using literature correlations.

The determination of the boiling regimes that govern the cooling process when plunging straws in liquid nitrogen constitutes an important issue when trying to optimize cryopreservation procedures. Furthermore, this information can lead to improvements in the design of cooling devices in the cryobiology field.
\end{abstract}

(c) 2014 Elsevier Inc. All rights reserved.

\footnotetext{
Statement of funding: The financial support for this research was provided by the following Institutions: (1) Facultad de Ciencias Agrarias, Universidad Católica Argentina (Ciudad Autónoma de Buenos Aires), (2) Centro de Investigación y Desarrollo en Criotecnología de Alimentos (CIDCA-CONICET), (3) Universidad Nacional de La Plata (Bs As), (4) and Agencia Nacional de Promoción Científica y Tecnológica (ANPCYT). The funding sources had no involvement in the development and analysis of the results presented in the present work.

* Corresponding author at: Depto. de Ingeniería Química, Facultad de Ingeniería, Universidad Nacional de La Plata and Centro de Investigación y Desarrollo en Criotecnología de Alimentos (CONICET-UNLP), Calle 47 y 116, La Plata 1900, Argentina.

E-mail address: mvsantosd@gmail.com (M.V. Santos).
}

\section{Introduction}

The knowledge of the thermodynamic process that a biological sample experiences during the cryopreservation procedures is of major importance. Specifically, the measurement of temperature changes in the sample can be used to calculate cooling rates and to determine whether a sample is vitrified or undergoes phase transition. When dealing with liquid nitrogen (LN2), the temperature difference between the fluid and the sample (which can be at near room temperature), is large enough to cause boiling of the liquid entering into the film boiling regime [7,31]. This determines a heat flux $(q)$ from the object to LN2 creating a pocket of nitrogen vapor around the solid which acts as an "insulator" retarding further heat transfer. Film boiling is also referred to as the 
"Leidenfrost effect". The object will cool down, rather slowly due to the low heat transfer rates and the "minimum heat flux" point will be reached at the Leidenfrost temperature transition $\left(T_{L}\right)$. Vapor film will then break off while the heat flux progressively increases as transition to the nucleate boiling regime is established [15]. This event is characterized by a steep increase of the heat flux up to a point called the "maximum heat flux" [7,24].

The first boiling curve experiments where done by Nukiyama in 1934 using horizontal heated wires in saturated water where both heat flux and temperature were recorded by controlling the power electrical input to the wire [21]. The experiment showed the hysteresis loop and was not able to obtain the entire boiling curve with the transitional stage of nucleate to film boiling since the temperature of the wire was not the controlled variable. Drew and Mueller [12] reproduced the entire curve by using organic fluids and a tube where water steam at elevated pressure condensed and hence the tube wall temperature was controlled by adjusting the steam pressure.

The boiling curve which corresponds to variation of the heat flux $(q)$ as a function of the excess wall temperature $\left(\Delta T=T_{\text {wall }}\right.$ $-T_{\text {sat }}$ ) depends on several relevant factors such as: (i) the type of cryogenic fluid used and its thermal properties, (ii) the material in contact with the fluid and its roughness which affects the nucleation sites and the $T_{L}$ [32], (iii) the relative position of the solid in the cryogenic fluid (vertical, horizontal, or in angle), and (iv) the geometry of the solid (plates, sphere, cylinders, or irregular shapes).

There is a lack of experimental information concerning the boiling curves in devices such as plastic straws containing biological samples. Plastic French straws are widely used in cryobiology and immersion in liquid nitrogen (LN2) is a common procedure in cryopreservation of biological samples. Specifically, there exists no certain information whether the cooling process is governed entirely by a film type or by a nucleate boiling regime, or a combination of both processes. Additionally it is important to assess the range of $\Delta T$ where each regime develops and the Leidenfrosttemperature transition $\left(T_{L}\right)$.

The objectives of the present study were: (i) to experimentally measure the time-temperature boiling curve of an ice-filled French straw when immersed in LN2 and to determine the boiling regimes that govern the process by applying a numerical finite element program that calculates the variable surface heat transfer coefficients; (ii) to validate the $h$ values using a French straw filled with a model biological fluid system (bovine semen-extender) which undergoes freezing upon cooling and therefore the thermophysical properties are temperature dependent; (iii) to determine the Leidenfrost-temperature transition $\left(T_{L}\right)$ and (iv) to corroborate the $h$ values obtained in this study with literature correlations for film and nucleate boiling in related systems.

\section{Materials and methods}

\section{Experimental measurements}

Cylindrical plastic straws used for bovine semen cryopreservation were obtained from AB Technology, Inc., Pullman, Washington, USA). The average external diameters, length and thickness were $D=2.81 \mathrm{~mm}, L=124 \mathrm{~mm}, e=0.21 \mathrm{~mm}$, respectively.

In order to determine the surface heat transfer coefficients at the straw-LN2 interface, the straw was filled with ultra-pure, reverse-osmosis filtered water (Milli-Q, Milipore Corporation, MA, USA) that freezes at $0 \pm 0.3^{\circ} \mathrm{C}$. The time-temperature curve was recorded using a thermocouple type $\mathrm{T}$ (Copper-Constantan) placed at the central axis of the straw. The outside diameter of the thermocouple was $0.22 \mathrm{~mm}$. The straw containing pure water was slowly swirled in Nitrogen vapor over the liquid nitrogen in a Dewar tank thus generating ice crystals. Thermo-physical properties of ice in the temperature range of -2 to $-194{ }^{\circ} \mathrm{C}$ were obtained from literature data $[10,11]$. Once the freezing plateau region was completed, ice was formed however to stabilize the initial temperature of the sample the straw was removed from the Dewar Tank and then rapidly immersed in a thermostatic bath containing ethylene glycol-water solution $(30 \% \mathrm{v} / \mathrm{v})$ at a constant temperature. Different experiments were carried out fixing the initial temperature of ice between $-2{ }^{\circ} \mathrm{C}$ and $-9{ }^{\circ} \mathrm{C}$ in the thermostatic bath. Afterwards the straw was rapidly plunged in liquid nitrogen using the Dewar canisters. The advantage of using ice in the straw is to avoid phase changes upon cooling (temperature range of $-2{ }^{\circ} \mathrm{C}$ to $-194^{\circ} \mathrm{C}$ ). The thermocouple was connected to an acquisition device (TESTO, Germany). Fig. 1 shows how the experimental arrangement.

\section{Mathematical modeling}

The system (plastic straw and internal material) can be described as two concentric finite cylinders of different substances: the inner material being either ice or biological cells (semen + extender) and the plastic straw. The partial differential equations that represent the heat transfer in the fluid that is submitted to the freezing process (Eq. (1)) and the plastic support (Eq. (2)) considering radial and axial coordinates have been thoroughly described in Santos et al. [28,29], and are as follows:

$$
\begin{aligned}
& \rho_{s}(T) C p_{s}(T) \frac{\partial T}{\partial t} r=\frac{\partial}{\partial r}\left(\left(k_{s}(T) r \frac{\partial T}{\partial r}\right)\right)+\frac{\partial}{\partial z}\left(\left(k_{s}(T) r \frac{\partial T}{\partial z}\right)\right) \\
& \rho_{p} C p_{p} \frac{\partial T}{\partial t} r=\frac{\partial}{\partial r}\left(\left(k_{p} r \frac{\partial T}{\partial r}\right)\right)+\frac{\partial}{\partial z}\left(\left(k_{p} r \frac{\partial T}{\partial z}\right)\right)
\end{aligned}
$$

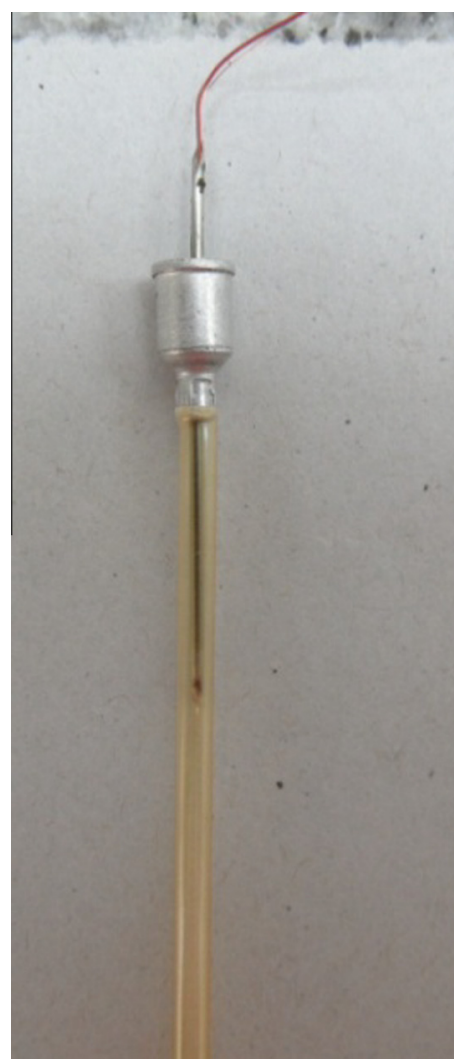

Fig. 1. Straw initially filled with pure water with the thermocouple threaded into the needle and mounted into the straw to avoid radial movement during the experiment. 
where $T$ is temperature, $\rho$ is the density, $C p$ specific heat, $k$ thermal conductivity.

The subscript $s$ corresponds to the inner material (ice or biological fluid) and $\mathrm{p}$ to the plastic material. In the case of the plastic support the thermophysical properties $\left(k_{p}, \rho_{p}, C p_{p}\right)$ are considered constant; in contrast the inner material have temperature dependent thermal properties. In the case of ice the phase change transition was not included in the studied temperature range, however for the biological fluid that undergoes freezing, a highly non-linear mathematical problem is established $[28,29]$.

The initial temperature condition was considered uniform in both material domains.

The convective boundary condition at the interface plastic support-LN2 is:

$-k_{p} \nabla T \cdot n=h\left(T_{\text {wall }}-T_{\text {ext }}\right)$

where $h$ is the surface heat transfer coefficient, $k_{p}$ is the plastic thermal conductivity, $T_{\text {wall }}$ is the variable surface wall temperature of the interface plastic support-LN2, $T_{\text {ext }}$ is the external temperature (in this case the saturation temperature of LN2 at atmospheric pressure), $\mathrm{n}$ is the normal outward vector, and $\nabla T$ is the temperature gradient evaluated at the surface.

The numerical program calculates the temperature profile as a function of time, in the straw and the fluid during the freezing process; especially the temperature at the wall which is used in the prediction of the heat flux by applying the convective boundary condition.

A subroutine that enables the introduction of a variable $h$ value with time was coded in Matlab language in the main program which was originally generated in the commercial software COMSOL. This subroutine allows the prediction of an $h$ value for each boiling regime.

Different heat transfer coefficients were introduced to simulate the temperature-time curve for straws; experimental and predicted temperatures for each proposed $h$ were compared. The heat transfer coefficient that minimized the Residual Sum of Squares given by Eq. (4) was selected.

$R S S=\sum\left(T_{\exp }-T_{\text {pred }}\right)^{2}$

\section{Thermal properties of bovine semen + extender}

In order to validate the previously obtained surface heat transfer coefficients for French straws filled with ice, experiments were carried out with straws containing a model biological fluid system (bovine semen-extender) which undergoes freezing upon cooling. Semen was obtained from five adult, Red Angus bulls of proven fertility and good body condition. Ejaculates were then diluted in a commercial tris-buffered extender (Triladyl, Minitube ${ }^{\circledR}$, Germany) containing egg yolk (20\% v/v) and glycerol $(6 \% \mathrm{v} / \mathrm{v})$ and adjusted to a final insemination dose of $10 \times 10^{6} \mathrm{sperm} / \mathrm{straw}$. The thermal data of the bovine semen + extender used as input information in the numerical program was: initial freezing temperature, bound water, heat of melting, specific heat, thermal conductivity and density. This information was obtained by experimental measurements in a Differential Scanning Calorimeter (DSC) and by applying mathematical models in a range of temperatures between -150 and $20^{\circ} \mathrm{C}$. All the thermophysical properties used in the model were reported in a previous work [28]. Additionally, thermal data at lower temperatures were compiled to increase the temperature range of data enhancing the accuracy of the models prediction. The thermal properties of ice in the range of -180 to $-100{ }^{\circ} \mathrm{C}$ were included in the calculations of the thermal properties
[10]. The latent heat of melting was $\Delta H_{m}=264.95 \mathrm{~kJ} / \mathrm{kg}$ and the unfrozen water determined by DSC was $4.88 \%$ (wet basis).

\section{Experimental design and statistical analysis}

Experimental time-temperature data obtained with plastic French straws submerged in LN2 using (i) ice and (ii) semen + extender fluid, were processed in order to obtain accurate average values of $h$ for each boiling regime. Four experiments for straws filled with ice and four experiments with semen + extender fluid were carried out providing 8 experimental data for an average $h$ value in film and nucleate boiling regimes. This procedure allowed the calculation of the standard deviations and confidence intervals for heat transfer coefficients.

ANOVA and Tukey's test were used to analyze significant differences among mean $h$ values $h(P<0.05)$.

\section{Results and discussion}

Determination of the surface heat transfer coefficients for ice-filled straws plunged in liquid nitrogen

The experiments with straws containing ice, that were plunged in liquid nitrogen, allowed the rigorous determination of the surface heat transfer coefficients avoiding any phase change in the cooling process.

Fig. 2a shows the experimental temperatures versus time and the predicted values assuming two different hypothesis: (i) considering film boiling regime during the entire cooling process (using a single and constant $h$ value) ; (ii) assuming film boiling for the first stage followed by nucleate boiling regime (higher $h$ value). Fig. $2 \mathrm{~b}-$ d show replicate runs.

As can be observed there is a lack of agreement between the experimental and predicted temperatures when a single constant value of $h$ was used over the entire cooling curve. However good agreement was achieved considering two regime stages during the cooling of straws. Note that since ice was used from the beginning, no plateau region is observed. The cooling curve showed an abrupt change in the slope which is attributed to the transition of film into nucleate boiling regime. This change in the cooling slope was also reported in other experiments with stainless steel blocks immersed in liquid Nitrogen [18]. The change in the rate of cooling can be attributed to the presence of two different regimes, first film and then nucleate boiling. During pool film boiling the excess wall temperature $(\Delta T)$ is at its maximum and the $h$ that best fitted all experimental results were in average $h=151.25 \mathrm{~W} / \mathrm{m}^{2} \mathrm{~K}$ for ice. During nucleate boiling a rapid drop of the temperature was observed and the $h$ value of $1347 \mathrm{~W} / \mathrm{m}^{2} \mathrm{~K}$ gave the best fit to the experimental temperatures for ice.

Validation of the surface heat transfer coefficients previously obtained using French straws filled with semen + extender

Fig. 3a shows experimental time-temperature values and the finite element numerical predicted curves for French straws filled with semen + extender assuming the same hypothesis as in Section 'Determination of the surface heat transfer coefficients for ice-filled straws plunged in liquid nitrogen': (i) considering film boiling regime during the entire cooling process (using a single constant $h$ value); (ii) assuming film boiling for the first stage $\left(h=150 \mathrm{~W} / \mathrm{m}^{2} \mathrm{~K}\right)$ followed by nucleate boiling regime $\left(h=1300 \mathrm{~W} / \mathrm{m}^{2} \mathrm{~K}\right)$. 
(a)

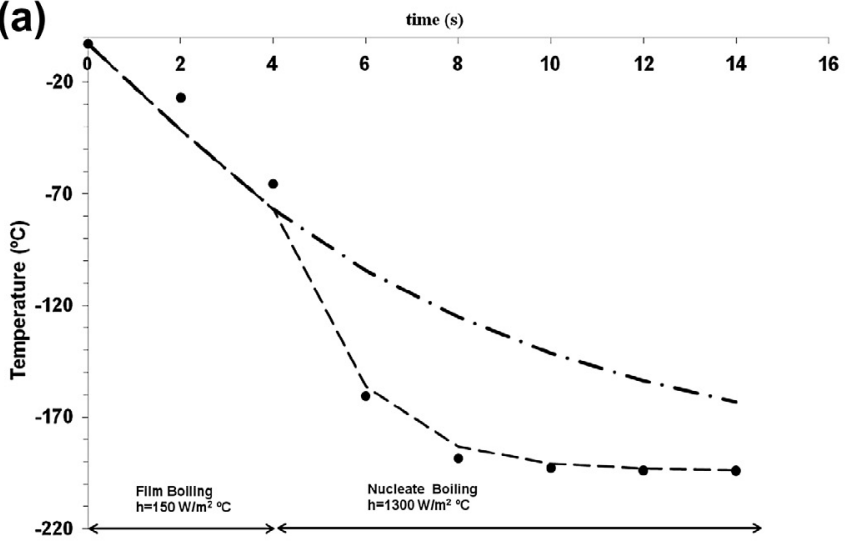

(c) 0

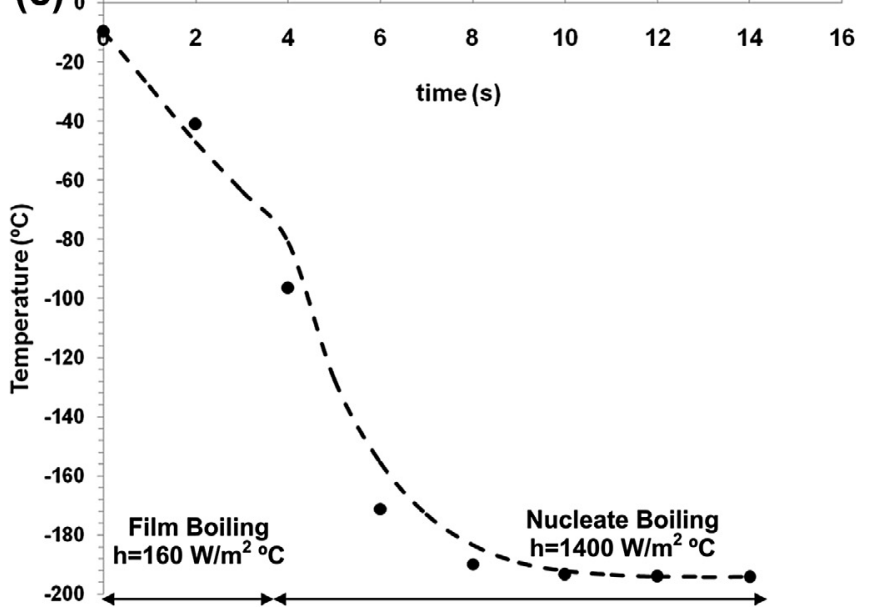

(b)

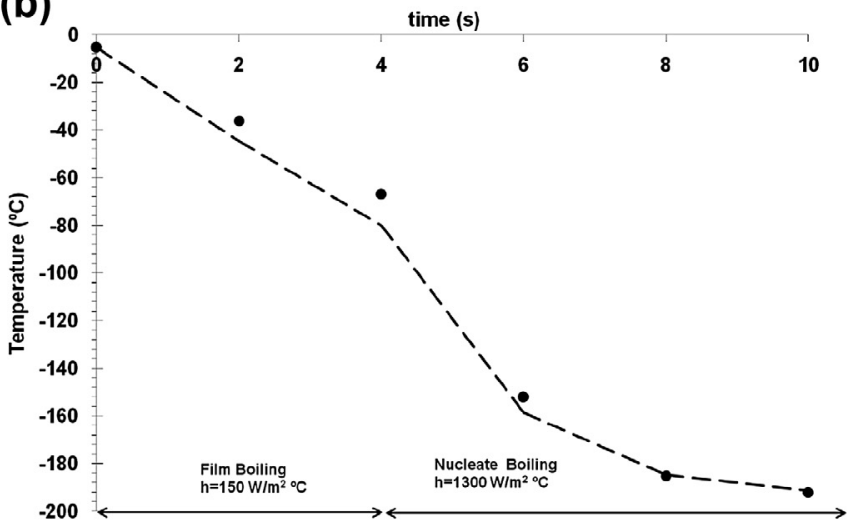

(d)

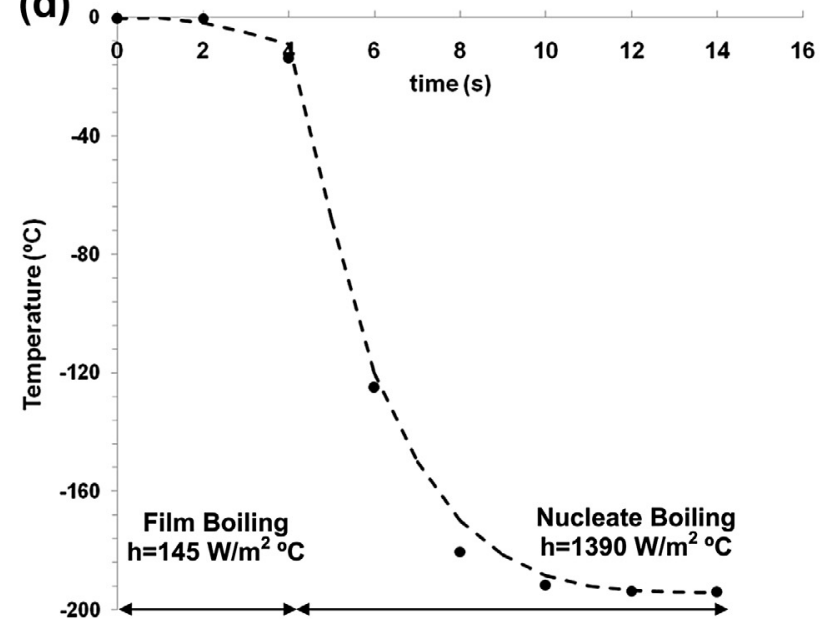

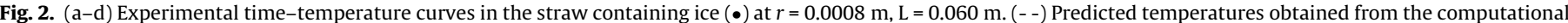

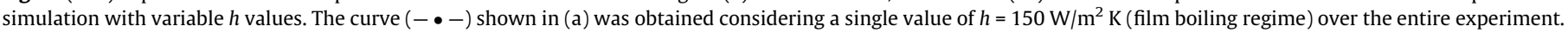

As it can be noted, good agreement between experimental and predicted values was observed when assuming film boiling for first stage $\left(h=150 \mathrm{~W} / \mathrm{m}^{2} \mathrm{~K}\right)$ and nucleate boiling regime $(h=1300 \mathrm{~W} /$ $\mathrm{m}^{2} \mathrm{~K}$ ) for the second stage. This observation reinforces the existence of two stage boiling regime phenomenon. The curve shows a mild plateau region which can be attributed to the phase change transition of water into ice in the semen sample. Afterwards, an abrupt slope change in the cooling curve develops and a rapid drop in the temperature is observed which corresponds to the transition of film to nucleate pool boiling similarly as it was explained for the ice system.

Fig. 3b-d shows replicate runs obtained with French straws containing semen + extender fluid and the numerical predictions using the $h$ values calculated by the numerical model.

Fig. 3e shows the predicted temperature profile in the straw at different radial positions. From the temperature profile it can be concluded that the temperature gradient in the semen + extender domain is lower in comparison with the temperature gradient in the plastic support, even though the thickness of the straw is only $0.21 \mathrm{~mm}$ compared to the $1.19 \mathrm{~mm}$ of biological fluid. This is attributed to the different thermophysical properties of the plastic support compared with the fluid, which in this case is temperature dependent due to freezing. This finding suggests that selection of the manufacturing material of the straw is an important factor that affects cooling rate, as was previously demonstrated by Sansinena et al. [27]. For the semen + extender experiments the $h$ that best fitted all experimental results were in average 145 and $1362 \mathrm{~W} / \mathrm{m}^{2} \mathrm{~K}$ for film and nucleate pool boiling, respectively.
Average surface heat transfer coefficient for film and nucleate pool boiling in plastic French straws

A biphasic fluid dynamic behavior with a first film boiling stage and then a nucleate pool boiling regime was observed in both systems analyzed (ice and semen + extender fluid).

The average $h$ values obtained and the corresponding confidence limits considering all the experiments with ice and semen + extender, were $148.12 \pm 5.4 \mathrm{~W} / \mathrm{m}^{2} \mathrm{~K}$ for film boiling regime and $1355 \pm 51 \mathrm{~W} / \mathrm{m}^{2} \mathrm{~K}$ for the nucleate pool boiling regime.

As expected, ANOVA showed that there were no significant differences between the $h$ values obtained with ice filled straws or with straws containing semen + extender for both boiling regimes.

In the present work the errors in the thermophysical properties (ice or semen + extender and also the plastic material) were minimized by using measured and estimated values as functions of the temperature (non-linear mathematical problem).

The thermocouple device has an internal absolute error of $0.5^{\circ} \mathrm{C}$ for each temperature measurement. The errors associated with the difference in the time-temperature curve and the predicted values which would affect the $h$ values estimated, can be attributed to factors such as the possible displacement in the thermocouple position inside the straw.

Heat flux as a function of excess wall temperature

The heat flux ( $q=h \Delta T$ ) as a function of the excess wall temperature $\left(\Delta T=T_{\text {wall }}-T_{\text {sat }}\right)$ was determined using the predicted wall 

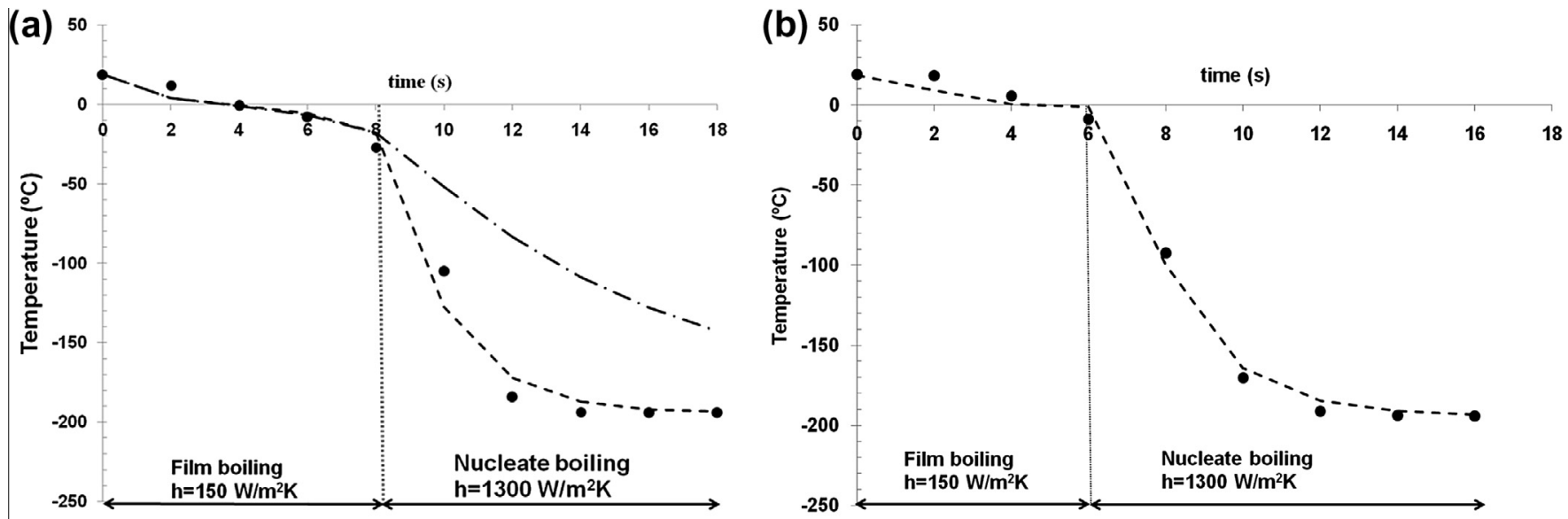

(C) 40
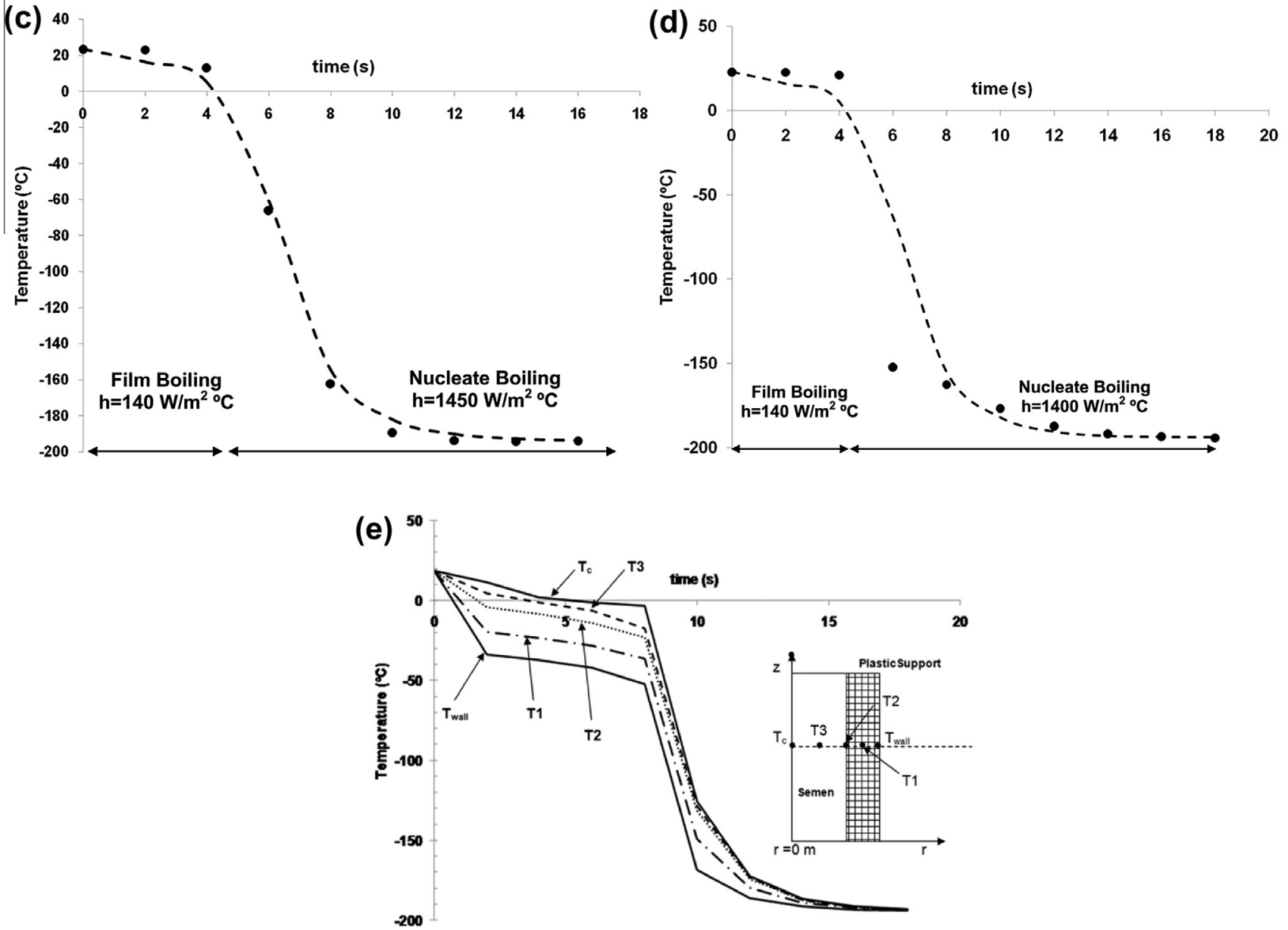

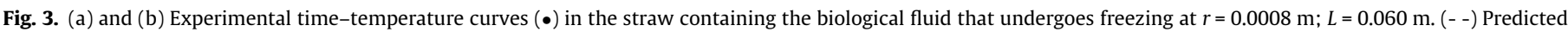

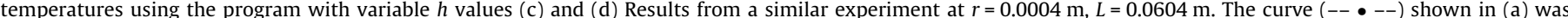

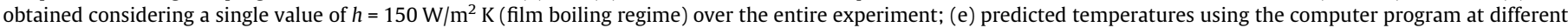

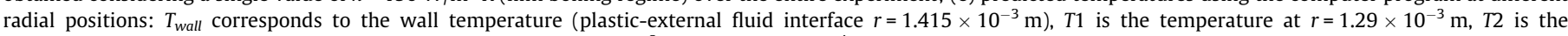
temperature at the interface plastic-semen + extender $\left(r=1.165 \times 10^{-3} \mathrm{~m}\right), T 3=7.74 \times 10^{-4} \mathrm{~m}$ in the semen + extender, $T_{c}$ at $r=0 \mathrm{~m}$ center of the straw.

temperature of the straw ( $\left.T_{\text {wall }}\right)$ and the $h$ values (Table 1$)$. The heat flux for straws filled with ice has a $q_{\min }$ value of $19555 \mathrm{~W} / \mathrm{m}^{2}$ which corresponds to an excess wall temperature value of $\Delta T=130.4{ }^{\circ} \mathrm{C}$, being the wall temperature $T_{\text {wall }}=-65.7^{\circ} \mathrm{C}$. The stable film boiling regime extends up to the point where the heat flux is at its minimum $\left(q_{\min }\right)$ corresponding to $(\Delta T)_{q \min }=T_{\text {wall }}-T_{\text {sat }}$. This $(\Delta T)_{q \text { min }}$ for the tested straw-liquid nitrogen system was in the range of $130-140^{\circ} \mathrm{C}$, that corresponds to a critical wall temperature range (Leidenfrost-temperature transition, $T_{L}$ ) of -66 to $-55^{\circ} \mathrm{C}$

In the case of the straw filled with the biological fluid the minimum flux, $q_{\min }=21,072 \mathrm{~W} / \mathrm{m}^{2}$ was obtained at an excess wall temperature $\Delta T=140.5{ }^{\circ} \mathrm{C}$ which corresponds to a wall temperature of $-55.52{ }^{\circ} \mathrm{C}$. When the straw surface temperature becomes 
Table 1

Heat flux $\left[\mathrm{W} / \mathrm{m}^{2}\right]$ and excess wall temperature $\Delta T$ obtained for the straw filled with ice or semen.

\begin{tabular}{|c|c|c|c|}
\hline \multicolumn{2}{|c|}{ Straws filled with ice } & \multicolumn{2}{|c|}{ Straws filled with Semen } \\
\hline$\Delta T\left({ }^{\circ} \mathrm{C}\right)$ & $q\left(\mathrm{~W} / \mathrm{m}^{2}\right)$ & $\Delta T\left({ }^{\circ} \mathrm{C}\right)$ & $q\left(\mathrm{~W} / \mathrm{m}^{2}\right)$ \\
\hline 190.7 & 28605.0 & 214.7 & 32205.0 \\
\hline 130.4 & 19555.0 & 162.4 & 24353.9 \\
\hline 99.3 & 129061.5 & 158.8 & 23820.3 \\
\hline 17.0 & 22155.1 & 154.3 & 23148.1 \\
\hline 6.1 & 7902.2 & 140.5 & 21072.0 \\
\hline \multirow[t]{5}{*}{3.2} & 4148.5 & 28.0 & 36403.2 \\
\hline & & 10.4 & 13484.4 \\
\hline & & 4.8 & 6177.7 \\
\hline & & 3.0 & 3835.4 \\
\hline & & 2.3 & 3018.8 \\
\hline
\end{tabular}

lower than this value there is a transition from film boiling to nucleate boiling and the heat flux increases up to a maximum value, afterwards it decreases and $\Delta T$ diminishes.

This $(\Delta T)_{q \min }$ depends on several important factors such as the type of cryogenic fluid used and its thermal properties, the material in contact with the fluid and its roughness which affect the nucleation sites and the transition or Leidenfrost temperature.

Additionally other factors are, the relative position of the immersed body in the cryogenic fluid (vertical, horizontal, or angle of surfaces in contact with the fluid), and the geometry of the solid (plates, sphere, cylinders, or irregular shapes). There are many reports in literature concerning the $(\Delta T)_{q \min }$ for several systems and configurations. Table 2 shows the reported values of $(\Delta T)_{q \min }$ and $T_{L}$ values for several objects when immersed in liquid nitrogen.

As can be observed $T_{L}$ is not a fixed temperature and depends on several factors such as geometry, dimensions, surface characteristics (polished and non-polished surfaces) [32] and the application of controlled variables during the experiment (heat flux or temperature).

It can be remarked that in polished metals the $(\Delta T)_{q \min }$ values are lower than those for plastic straw since there are less active sites where bubble formation can take place. Roughness also triggers the nucleation of bubbles and thus tends to increase the temperature $T_{L}$. Surface roughness and the hydrophobicity of the fluid affect the Leidenfrost temperature transition [32].

Comparison of the obtained surface heat transfer coefficient with literature correlations for pool film boiling

Film boiling regime for a cylinder immersed in LN2

The film boiling is characterized by a vapor film covering the solid surface frequently called a non-wetting situation $[2,5,25]$; due to the low thermal conductivity of the N2 vapor with respect to the liquid nitrogen there exists a very large temperature difference between the solid and the liquid N2. The vapor insulates the straw from the LN2 and also prevents the nucleation of bubbles owing to the absence of solid/liquid contact limiting the heat flux transfer. The critical temperature transition (Leidenfrost temperature, $T_{L}$ ), may depend on the nature of the surface and specifically on its roughness $[3,4]$. Although film boiling is established when there is very large temperature difference between the surface and fluid, it is important to predict the minimum excess temperature difference that must exist to sustain that regimen [20].

Bromley [6] proposed the following correlation for vertical tubes.

$h=C 2 \times\left(\frac{k_{v}^{3} \rho_{v}\left(\rho_{l}-\rho_{v}\right) g \Delta H_{e}}{\mu_{v} L \Delta T}\right)^{1 / 4}$

where $\mu=$ viscosity (lb/(ft hr)), $g=$ gravitational constant $\left(\mathrm{ft} / \mathrm{hr}^{2}\right)$, $L=$ length of the straw (ft), $\Delta T=T_{\text {wall }}-T_{\text {sat }}\left({ }^{\circ} \mathrm{F}\right), \Delta H=$ latent heat of vaporization and $\Delta H_{e}=$ latent heat of vaporization plus the sensible heat of the vapor $\Delta H_{e}=\Delta H+0.34 C p_{v}\left(T_{\text {wall }}-T_{\text {sat }}\right)(\mathrm{BTU} / \mathrm{lb}$.), $k=$ thermal conductivity (BTU/(hr $\left.\left.\mathrm{ft}{ }^{\circ} \mathrm{F}\right)\right), \rho=$ density $\left(\mathrm{lb} . / \mathrm{ft}^{3}\right)$, $\mathrm{h}\left(\mathrm{BTU} /\left(\mathrm{hr} \mathrm{ft}^{2}{ }^{\circ} \mathrm{F}\right)\right)$ and subscripts $v$ and $l$ correspond to the vapor and liquid phase, respectively.

The coefficient $C 2=0.943$ is used when the liquid is supposed to move with the same velocity as the vapor [16]. The long flow path results in a thick film which can be unstable and develop turbulence.

When the vapor rises, a critical Reynolds number can be reached at the critical height (Lcr), which can be estimated by the following correlation [20]:

$\operatorname{LCr}=\frac{100 \mu_{v}\left(\Delta H_{e} / \Delta H\right)}{2 k_{v} \Delta T}\left[\frac{200 \mu_{v}^{2}}{g \rho_{v}\left(\rho_{l}-\rho_{v}\right)}\right]^{1 / 3}$

Lcr indicates the minimum length that must exist for the vaporliquid interface to become unstable and allow the formation of vapor jets that generate the overhead bubbles. In Eq. (6) Lcr is expressed in (ft).

For objects with a height $L>$ Lcr, the heat transfer coefficients can be calculated by the following equation [1]:

$h=0.20 \rho_{v} C p_{v}\left(\frac{g^{2} L \mu_{v}}{\rho_{v}}\right)^{1 / 5}\left(\frac{\left(\rho_{l}-\rho_{v}\right)}{g \rho_{v}}\right)^{2 / 5}\left(\frac{C p_{v} \Delta T}{\Delta H}\right)^{1 / 5}$

where his expressed in $\mathrm{BTU} / \mathrm{h} \mathrm{ft}^{2}{ }^{\circ} \mathrm{F}$.

In the correlations reported by Sakurai et al. [26], Kida et al. [19], Galloway and Mudawar [13], for film boiling regime, the characteristic length is the critical Taylor wavelength $(\lambda c)$ instead of the cylinder length. During boiling near the minimum heat flux, a large amount of vapor is glutted around the object and it tries to buoy outward. Near $T_{L}$ the instability that occurs at the interface between vapor and liquid N2 leads to the formation of waves in the vapor film that release the vapor into jets feeding overhead bubbles or slugs perpendicular to the surface and separated by distances denominated Taylor critical wavelength [20]. This wavelength can be predicted as a result of balancing forces of surface tension against inertia and gravity $[13,21]$ as:

Table 2

Literature values of $(\Delta T)_{q \min }$ for several metallic objects immersed in liquid nitrogen

\begin{tabular}{|c|c|c|c|c|}
\hline System & Dimensions & $(\Delta T)_{q \min }\left({ }^{\circ} \mathrm{C}\right)$ & $\mathrm{TL}\left({ }^{\circ} \mathrm{C}\right)$ & Refs. \\
\hline Cooper sphere & Diameter $2.89 \mathrm{~cm}$ & 48 & -148 & [9] \\
\hline Stainless steel block & $6.0 \times 6.0 \times 1.75 \mathrm{~cm}$ & 53 & -143 & [18] \\
\hline Cooper cylinder $^{\mathrm{a}}$ & Diameter $5.08 \mathrm{~cm}$ Length $7.25 \mathrm{~cm}$ & 25 & -171 & {$[22]$} \\
\hline Stainless steel cylinder ${ }^{\mathrm{a}}$ & Diameter $4.13 \mathrm{~cm}$ & 76 & -120 & {$[8]$} \\
\hline Stainless steel cylinder ${ }^{\mathrm{a}}$ & Not reported & 80 & -116 & [17] \\
\hline Copper spheres & Diameter $2.54-0.635 \mathrm{~cm}$ & 45 & -151 & [23] \\
\hline Platinum cylinder ${ }^{\mathrm{a}}$ & Diameter $0.60 \mathrm{~cm}$ & 40 & -156 & [26] \\
\hline Platinum wires & Diameter 0.1 to $1.0 \mathrm{~mm}$ & 100 & -96 & [19] \\
\hline
\end{tabular}

\footnotetext{
a In this case, spatial position for cylinders (vertical/horizontal) was not reported.
} 
$\lambda_{c}=2 \pi\left[\frac{\sigma}{g\left(\rho_{l}-\rho_{v}\right)}\right]^{1 / 2}$

These waves were experimentally observed for tubes in LN2 during film boiling in Kida et al. [19] and Hsu and Westwater [16]. The correlation proposed by Sakurai et al. [26]:

$\operatorname{Nu}\left(\lambda_{c}\right)=0.82\left(M_{\left(\lambda_{c}\right)}\right)^{\frac{1}{4}}$

being $\mathrm{Nu}$ the Nusselt number defined as $\mathrm{Nu}=\frac{\lambda_{c} * h}{k_{v}}$

where

$M_{\left(\lambda_{c}\right)}=\frac{\left[\frac{\mathrm{Gr}_{v_{, \lambda}, \lambda_{c}} \operatorname{Pr}_{v} L^{\prime}}{C p_{v} \Delta T}\right]\left[\frac{E^{3}}{\left\{1+\frac{E}{S p \mathrm{Pr}_{l}}\right\}}\right]}{\left(\operatorname{RPr}_{l} S_{p}\right)^{2}}$

$\operatorname{Gr}_{\left(\lambda_{c}\right)}=\frac{g \lambda_{c}^{3}\left(\rho_{l}-\rho_{v}\right)}{\mu_{v}^{2}} \rho_{v}$

is the Grashof number

$L^{\prime}=\Delta H+0 . C p_{v}\left(T_{\text {wall }}-T_{\text {sat }}\right)$

where $L^{\prime}$ is the latent heat of vaporization $(\Delta H)$ plus sensible heat of vapor phase

$\operatorname{Pr}_{v}=\frac{C p_{v} \mu_{v}}{k_{v}}$

$\operatorname{Pr}_{v}$ is the Prandtl number for the vapor phase

$\operatorname{Pr}_{l}=\frac{C p_{l} \mu_{l}}{k_{l}}$

$\operatorname{Pr}_{l}$ is the Prandtl number for the liquid phase

$S_{p}=\frac{\left(C p_{v} \Delta T\right)}{L^{\prime} \operatorname{Pr}_{v}}$

$E=(A+C \sqrt{B})^{1 / 3}+(A-C \sqrt{B})^{1 / 3}$

$A=\frac{1}{4} R^{2} S_{p}^{2} \operatorname{Pr}_{l}^{2}$

$B=\frac{-32}{27} R^{2} S_{p} P r_{l}+\frac{1}{4} S_{p}^{2} \operatorname{Pr}_{l}^{2}$

$C=\frac{1}{2} R^{2} S_{p} \operatorname{Pr}_{l}$

$R=\left[\frac{\rho_{v} \mu_{v}}{\rho_{l} \mu_{l}}\right]^{1 / 2}$

Eq. (9) is independent of the tube length since its characteristic length is $\lambda_{c}$ and was applied by different researchers $[14,19,18]$.

The configuration of the solid (vertical, horizontal od in angle) affects the $h$ value $[16,26]$.The average $h$ for vertical cylinders is 1.25 times higher than that for horizontal cylinders [26].

The correlations were coded in Matlab using variable $T_{\text {wall }}$ as a function of time obtained from the numerical solution. Values of $h$ reported in the present work correspond to the average value over the time period assayed.

Bromley equation for vertical cylinders (Eq. (5)) with a constant value of $C 2=0.943$ (using $L=0.12 \mathrm{~m}$ that is the length of the straws) predicted $h=156.03 \mathrm{~W} / \mathrm{m}^{2} \mathrm{~K}$.

Eq. (7) proposed by Bankoff [1] for vertical slabs assuming that the vapor is no longer in a laminar flow (turbulence fluid-dynamic behavior) resulted in $h=159.38 \mathrm{~W} / \mathrm{m}^{2} \mathrm{~K}$.
The critical lengths (Lcr) calculated using Eq. (6) were in the range of $8.6-17.2 \mathrm{~mm}$. This would indicate that for a vertical surface the vapor flow can remain laminar to a maximum height of $1.72 \mathrm{~cm}$

Sakurai Eqs. (9)-(20) estimated a characteristic length for liquid nitrogen $\lambda_{C}=6.6 \mathrm{~mm}$, (same value as was reported in Kida et al. [19]) resulting in an average value of $h=148.2 \mathrm{~W} / \mathrm{m}^{2} \mathrm{~K}$.

The $h$ value obtained by using Eq. (5) [6] for film boiling resulted in a value of $151 \mathrm{~W} / \mathrm{m}^{2} \mathrm{~K}$; Eq. (7) [1] provided $h=159 \mathrm{~W} / \mathrm{m}^{2} \mathrm{~K}$, and Eq. (9) [26] a value of $h=148 \mathrm{~W} / \mathrm{m}^{2} \mathrm{~K}$.

The value predicted by the numerical model developed in the present work was $148.12 \mathrm{~W} / \mathrm{m}^{2} \mathrm{~K}$, which is in excellent agreement with the literature correlations for vertical tubes.

\section{Comparison of the obtained surface heat transfer coefficient with literature correlations for nucleate boiling regime}

In the present work the mean $h$ value for nucleate boiling regime in vertical tubes that fitted the experimental results for straws was $1355 \pm 51 \mathrm{~W} / \mathrm{m}^{2} \mathrm{~K}$. The pool nucleate boiling of nitrogen has been extensively studied by Seader et al. [30]; in their work the $h$ values were in the range of $946.3-7993 \mathrm{~W} / \mathrm{m}^{2} \mathrm{~K}$ that agree with the results obtained in the present work.

\section{Conclusions}

Measurement of experimental time-temperature curves of plastic French straw filled with ice and immersed in LN2 was carried out enabling the estimation of the surface heat transfer coefficients by applying a numerical finite element program. A specific subroutine was coded in the program in order to calculate a variable $h$ with time since two boiling regime, film followed by nucleate pool boiling, were detected to occur during the cooling process.

The existence of film and nucleate pool boiling regimes was validated by additional experiments using French straws filled with bovine semen + extender fluid, plunged in liquid nitrogen and comparing the time-temperature curves with the numerical predictions. Since this system freezes upon cooling, their temperature dependent thermophysical properties were taken into account in the computer code, as well as the variable surface heat transfer coefficients during the different boiling regimes. A good agreement was obtained between the experimental temperature profiles and the numerical predictions during cooling of straws containing bovine semen + extender, confirming the reliability of the previously determined heat transfer coefficients $\left(148 \mathrm{~W} / \mathrm{m}^{2} \mathrm{~K}\right.$ for film boiling and $1355 \mathrm{~W} / \mathrm{m}^{2} \mathrm{~K}$ for nucleate boiling).

Calculated values of heat flux $(q)$ vs. $\Delta T$, of straws placed vertically in liquid nitrogen were determined; this allowed the prediction of the Leidenfrost temperature, $q_{\min }, q_{\max }$ and the minimum $\Delta T$ necessary to sustain a film type behavior.

The calculated surface heat transfer coefficients for film and nucleate pool boiling during immersion in liquid nitrogen were also corroborated using literature correlations for related systems and configurations.

The determination of the different boiling regimes that govern the cooling process when plunging straws in liquid nitrogen constitutes an important issue when trying to optimize cryopreservation procedures. Furthermore, this information can lead to improvements in the design of cooling devices in the cryobiology field.

\section{Acknowledgments}

The authors gratefully acknowledge the financial support from the following institutions that funded this research work: Facultad 
de Ciencias Agrarias, Universidad Católica Argentina, Ciudad Autónoma de Buenos Aires, Centro de Investigación y Desarrollo en Criotecnología de Alimentos (CIDCA-CONICET), Universidad Nacional de La Plata, and Agencia Nacional de Promoción Científica y Tecnológica (ANPCYT)-ARGENTINA. They also thank Mr. Vicente Valenti for his collaboration in the laboratory experiments.

\section{References}

[1] S.G. Bankoff, Chem. Eng. Progress AIChE 4 (1958) 22-24.

[2] R.F. Barron, Cryogenic Heat Transfer, Taylor and Francis, Philadelphia, 1999.

[3] J.D. Bernardin, I. Mudawar, J. Heat Transf. 121 (1999) 894-903.

[4] J.D. Bernardin, C.J. Stebbins, I. Mudawar, J. Heat Mass Transfer 40 (1997) 73-88.

[5] B.P. Breen, J.W. Westwater, Chem. Eng. Prog. 58 (7) (1962) 67-72.

[6] L.A. Bromley, Chem. Eng. Prog. 46 (1950) 221-227.

[7] T.D. Bui, V.K. Dhir, J. Heat Transfer Trans ASME 107 (1985) 764-771.

[8] E. Chao, M. Helgeson, M. Kulkarni, P. Vaddi, Transport Process Lab team 3 , Carnegie Mellon University, Pittsburgh, 2003.

[9] N. Chase, B. Choi, P.M. Carrica, Int. J. Mech. Eng. Educat. 41 (2013) 212.

[10] J. Choi, J.C. Bischof, Cryobiology 60 (2010) 52-70.

[11] Y. Choi, M.R. Okos, Effects of temperature and composition on the therma properties of foods, in: M. Le Magher, P. Jelen (Eds.), P. Food Eng. Appl. Elsevier Applied Science Publishers, New York, 1986, pp. 93-103.

[12] T.B. Drew, A.C. Mueller, Trans. AlChE 33 (1937) 449-471.

[13] J.E. Galloway, I. Mudawar, J. Heat Mass Transfer. 35 (1992) 1247-1260.

[14] M.A. Hassan, D.M. Hashim, R.A. Rahman Pertanika, J. Sci. Technol. 8 (1985) 79
[15] Y.Y. Hsu, NASA TM TECHNICAL PAPER Cryogenic Engineering Conference, 1970.

[16] Y.Y. Hsu, J.W. Westwater, Chem. Eng. Prog. Symp. 56 (1960) 15-24.

[17] B. Hui, G. Kim, A. Edison, J. Kim, A. Chang, Transport Laboratory Experiment 3, Carnegie Mellon University, Pittsburgh, 2006.

[18] T. Jin, J. Hong, H. Zheng, K. Tang, Z. Gan, J. Zhejiang Univ. Sci. A 10 (2009) 691696.

[19] M. Kida, Y. Kikuchi, O. Takahashi, I. Michiyoshi, J. Nucl. Sci. Technol. 18 (1981) 501-513.

[20] F. Kreith, Principles of Heat Transfer, third ed., Harper and Row Publishers, New York, 1973.

[21] J.H. Lienhard IV, J.H. Lienhard V, A Heat Transfer Textbook, third ed., Phlogiston Press, Massachusetts, 2008.

[22] T.W. Listerman, T.A. Boshinski, L.F. Knese, Am. J. Phys. 54 (1986) 554-558.

[23] E.W. Lewis, H. Merte, J.A. Clark, AIChE (1965).

[24] S. Nishio, T. Ozu, Proc. of 25th National Heat Transfer Symposium of Japan, 1988, pp. 283-285.

[25] D. Quéré, Annu. Rev. Fluid Mech. 45 (2013) 197-215.

[26] A. Sakurai, M. Shiotsu, K. Hata, Nucl. Eng. Des. 120 (1990) 271-280.

[27] M. Sansinena, M.V. Santos, N. Zaritzky, R. Baeza, J. Chirife, Cryoletters 31 (2010) 120-129.

[28] M.V. Santos, M. Sansinena, N. Zaritzky, J. Chirife, Cryobiology 66 (2013) 30-37.

[29] M.V. Santos, M. Sansinena, N. Zaritzky, J. Chirife, Cryoletters 34 (2013) 158165.

[30] J.D. Seader, W.S. Miller, L.A. Kalvinskas. National Aeronautics and Space Administration Washington (NASA) D.C., 1965.

[31] N.V. Suryanarayana, H. Merte Jr., J. Heat Transfer Trans ASME 94 (1972) 377384.

[32] I.U. Vakarelski, N.A. Patankar, J.O. Marston, D.Y.C. Chan, S.T. Thoroddsen, Nature 489 (2012) 274-277. 